13. Haber ET, Koerner T, Page LB, Kliman B, Parnobe AJ 1969 Application of radioimmunoassay for angiotensin $I$ to the physiologic measurements of plasma renin activity in normal human subjects. $\mathrm{J}$ Clin Endocrinol Metab 29:1349

14. Hollenberg NK, Williams GH, Burger B, Hooshmand I 1975 The influence of potassium on the renal vasculature and the adrenal gland, and their responsiveness to angiotensin II in normal man. Clin Sci Mol Med 49.527

15. Ito $T$, Woo J, Haning R, Horton R 1972 A radioimmunoassay for aldosterone in human peripheral plasma including a comparison of alternate techniques. $\mathrm{J}$ Clin Endocrinol Metab 34:106

16. Jones CT, Ritchie JWK 1976 Endocrine and metabolic changes associated with periods of spontaneous hypoxia in fetal sheep. Biol Neonate 29.286

17. Jones CT, Ritchie JWK 1977 Corticosteroid inhibition of adrenocorticotrophin secretion in the foetal sheep. $J$ Endocrinol $72: 245$

18. Laragh $\mathrm{JH}$, Sealey JE 1973 The renin-angiotensin-aldosterone hormonal system and regulation of sodium, potassium and blood pressure homeostasis In: Orloff J, Berliner RW (eds): Handbook of Physiology. Washington, DC American Physiological Society, pp 831-908

19. McCaa RE, McCaa CS, Cowley AW, Ott CE, Guyton AC 1972 Stimulation of aldosterone secretion by hemorrhage in dogs after nephrectomy and decapitation. Circ Res 32:356

20. Pasqualini JR, Wiqvist N, Diczfalusy E 1966 Biosynthesis of aldosterone by human foetuses perfused with corticosterone at midterm. Biochim Biophys Acta $121: 430$

21. Robillard JE, Gomez RA, Meernik JG, Kuehl WD, VanOrden D 1982 Role of angiotensin II on the adrenal and vascular responses to hemorrhage during development in fetal lambs. Circ Res 50:645

22. Robillard JE, Gomez RA, VanOrden D, Smith FG, Jr. 1982 Comparison of the adrenal and renal responses to angiotensin II in fetal lambs and adult sheep. Circ Res 50:140

23. Robillard JE, Weitzman RE 1980 Developmental aspects of the fetal renal response to exogenous arginine vasopressin. Am J Physiol 238:F407

24. Robillard JE, Weitzman RE, Burmeister L, Smith FG, Jr 1981 Developmental aspects of the renal response to hypoxemia in the lamb fetus. Circ Res 48:128

25. Siegel SR 1981 Amniotic fluid concentrations of renin and aldosterone during development in the fetal sheep. Pediatr Res 15:1419

26. Siegel SR, Fisher DA 1980 . Ontogeny of the renin-angiotensin-aldosterone system in the fetal and newborn lamb. Pediatr Res 14.99

27. Siegel SR, Oakes G. Palmer 1981 Effects of angiotensin II on blood pressure, plasma renin activity, and aldosterone in fetal lambs. Dev Pharmacol Ther 3:144

28. Siegel SR, Oakes G, Palmer S 1981 Transplacental transfer of aldosterone and its effects on renal function in the fetal lamb. Pediatr Res 15:163

29. Wallenstein S, Zucker CL, Fleiss JL 1980 Some statistical methods useful in circulation research. Circ Res 47:1

30. Williams GH, Dluhy RG, Underwood RH 1970 The relationship of dietary potassium intake to the aldosterone stimulating properties of $\mathrm{ACTH}$. Clin Sci 39:489

31. Wintour EM, Barnes A, Cahill F, Hardy KJ, Horacek I Scoggins BA 1979 Potassium: aldosterone relationship in pregnant ewes and chronically cannulated ovine fetuses. Pediatr Res 13:265

32. Wintour EM, Brown EH, Denton DA, Hardy KJ, McDougall JG, Oddie CJ Whipp GT 1975 The ontogeny and regulation of corticosteroid secretion by the ovine foetal adrenal. Acta Endocrinol 79:301

33. Wintour EM, Brown EH, Denton DA, Hardy $\mathrm{KJ}$, MCDougall JG Robinson PM, Rowe EJ, Whipp GT 1977 In vitro and in vivo adrenal cortical steroid production by fetal sheep: effect of angiotensin II, sodium deficiency and ACTH. In: Conti C (ed): Research on Steroids, Vol VII. Amsterdam, Eisevier/North-Holland, pp 475-485

34. Wintour EM, Coghlan JP, Hardy KJ, Lingwood BE, Rayner M, Scoggins BA 1980 Placental transfer of aldosterone in the sheep. J Endocrinol 86:305

35. This research was supported by United States Public Health Service Grants HD-1 1466 and HL-14388 and American Heart Association Grant 79-809. Jean E. Robillard is the recipient of Research Career Development Award HD-00254. Nancy A. Ayres is supported by Training Grant T-32-HL-07413 04. R. Ariel Gomez is the recipient of National Kidney Foundation of Iowa Fellowship Award 15314. Kenneth T. Nakamura is the recipient of National Research Service Award 17429. Fred G. Smith, Jr. is the recipient of American Heart Association, Iowa Affiliate, Grant 83-G-38.

36. Requests for reprints should be addressed to: Jean E. Robillard, M.D. Pediatric Nephrology Division, 225 Med Labs, University of lowa College of Medicine, lowa City, IA 52242

37. Received for publication July $18,1983$.

38. Accepted for publication August 2, 1983.

\title{
Developmental Aspects of Renal $\beta$-Amino Acid Transport. IV. Brush Border Membrane Response to Altered Intake of Sulfur Amino Acids
}

\author{
RUSSELL W. CHESNEY, ${ }^{(41)}$ NAOMI GUSOWSKI, AND MARY THEISSEN \\ Pediatric Renal Disease Laboratory, Department of Pediatrics, University of Wisconsin, Center for Health \\ Sciences, Madison, Wisconsin, USA
}

\section{Summary}

Taurinuria is characteristic of the immature rat. The capacity of the kidney to accumulate the $\beta$-amino acid taurine and $D$ glucose was examined using isolated brush border membrane vesicles (BBMV) prepared from 28 -day-old rats. Taurine accumulation was inversely proportional to osmolarity, indicating uptake rather than binding, and taurine accumulation was $\mathrm{Na}^{+}-$ dependent. BBMV from 28 -day rats did not accumulate D-glucose to the same degree as in adult BBMV, and the initial rate of uptake was slower. Taurine uptake had a similar $K_{m}$ and $V_{\text {max }}$ in BBMV from immature rats. Despite similarities in the kinetics of taurine uptake, higher urinary taurine concentrations are found in younger rats, suggesting that other factors, such as an efflux block, account for the taurinuria of young animals.

A diet low in methionine and taurine (LTD) given for 7 days resulted in a lower excretion and fractional excretion of taurine than in animals fed a normal sulfur amino acid diet (NTD). A high taurine diet (HTD) causes excessive taurinuria. These patterns of excretion are reflected at the brush border membrane surface with greater uptake after the LTD and reduced uptake after the HTD. A kinetic analysis of adult and 28-day-old animal BBMV reveals that the $V_{\max }$ of accumulation is altered by diet, whereas the $K_{m}$ remains unchanged. The $V_{\text {max }}$ is higher in BBMV from LTD animals and lower in BBMV from HTD animals. The kinetics of uptake are similar in adult and 28-day-old rat vesicles 
on a given diet. Thus, in addition to ontogenic changes in taurine excretion, there is an adaptive response to dietary alteration present at the brush border surface.

\section{Abbreviations}

\section{LTD, low sulfur-amino acid diet}

NTD, normal sulfur-amino acid diet

HTD, taurine-supplemented diet

Hepes, 4-(2-hydroxyethyl)-1-piperazineethanesulfonic acid BBMV, brush border membrane vesicles

The renal tubule epithelium is involved in the process of the reabsorption and conservation of nutrients that appear in the glomerular filtrate. Both ions and organic solutes are retained, and this retention is accentuated under states of reduced dietary intake. Sodium, potassium, and phosphate are conserved when the diet is depleted of these ions $(15,36,37)$, and the term renal adaptation is used to indicate this enhanced accumulation. More recently, our laboratory $(14,17,19)$ and Rozen et al. $(31,32)$ have shown that the $\beta$-amino acid taurine is conserved by the renal epithelium after ingestion of various diets that are deficient in the sulfur-containing amino acids: methionine, cysteine, and taurine.

Taurine is a sulfur-containing $\beta$-amino acid which is found in the muscle, brain, and myocardium of mammals but whose biological role is uncertain $(22,39)$. Taurine is clearly important in the conjugation of bile acids to form water-soluble bile salts, and it may serve to lower the excitability of membranes in the central nervous system, spinal cord, myocardium, and retina Hence, it may be mandatory that this nutrient be conserved in times of deficient dietary intake.

We have previously shown that full-grown rats fed a sulfuramino acid-deficient diet have a reduction in the urinary excretion of taurine paralleled by enhanced accumulation of taurine by isolated tubules and brush border membrane vesicles prepared from the renal cortex $(14,17,19)$. A diet containing normal amounts of methionine and excess taurine $(3 \%)$ will result in the hyperexcretion of taurine and in reduced accumulation of taurine by tubules and vesicles. This adaptive response appears to be related to a change in the $\mathrm{V}_{\max }$ of transport with no alteration in the $\mathrm{K}_{\mathrm{m}}$ or affinity of the transport site for taurine. Accordingly, these changes indicate that this renal response serves to conserve taurine during periods of deprivation and to dispose of this amino acid during periods of dietary excess.

We have used the isolated brush border membrane vesicle technique to examine the ontogeny of this renal adaptive response to changes in amino acid composition of the diet. In this paper, we report that the capacity of the renal epithelium to adapt to alterations in the dietary intake of sulfur-containing amino acids is present within 1 week of weaning.

\section{MATERIALS AND METHODS}

Animals. Sprague-Dawley rats (King Laboratories, Fitchburg, WI) were used in all studies. Rats were fed one of three diets: LTD, NTD, HTD, prepared as described previously $(17,19)$. Briefly, all diets contained $20 \%$ soy protein. In addition, the LTD contained $0.2 \%(\mathrm{w} / \mathrm{w})$ methionine, $0.3 \%$ cysteine, and no taurine; the NTD contained $0.7 \%$ methionine and $0.7 \%$ cysteine; and the HTD contained 3\% crystalline taurine, $0.7 \%$ methionine, and $0.7 \%$ cysteine. Adult rats were fed one of the three diets for 14 days prior to sacrifice. Previous studies have shown that this time period is sufficient to permit a renal adaptive response to each diet (19), although the adaptive response is seen after only 6 days on the diet $(13,14)$. Rats of age 28 days (immature) were also used. These rats were fed one of the three diets from weaning at age 21 days until day 28 or for 7 days. A few 28-day-old rats had been fed either the low sulfur-amino acid or the normal diets for 3 days (days 25-28) to further assess the response of the immature kidney to dietary change. Urine and plasma collections were always performed on days 58-60 of life for adult rats and on day 28 for immature rats.

On the morning of sacrifice, animals were placed in metabolic cages with access to water only. Animals remained in cages for 3 to $6 \mathrm{~h}$, after which a timed urine sample was collected and its volume determined; the urine specimens were then rapidly frozen. Blood was removed from the bifurcation of the iliac arteries, placed on ice in heparinized tubes, and centrifuged at 10,000 $\mathrm{rpm}$. Hemolyzed plasma samples were rejected. Plasma taurine concentrations were determined only in plasma samples with a distinct buffy coat, since both leukocytes and platelets contain taurine in high concentrations (9).

Urine and plasma taurine and creatinine were measured by previously described methods $(9,11)$. The fractional excretion of taurine and the endogenous creatinine clearance was calculated from these values.

No attempt was made to pair-feed animals, but the animals ingesting the LTD, which contained reduced methionine and cysteine, consistently ingested more chow than all other groups.

Membrane vesicle preparation. Renal cortex brush border membrane vesicles were isolated by a series of differential centrifugations using a modification of the method of Booth and Kenny (4). Rats were placed under anhydrous ether anesthesia and exsanguinated; their kidneys were removed, decapsulated, and placed in cold $\left(4^{\circ} \mathrm{C}\right)$ saline. Renal cortex tissue was cut away. Samples of between 1.5 and $6 \mathrm{~g}$ wet weight were homogenized in 20 volumes of $0.5 \mathrm{M}$ D-mannitol, $2 \mathrm{mM}$ Tris- $\mathrm{HCl}(\mathrm{pH} 7.4)$, and $10 \mathrm{mM}$ Hepes (THM) for $5 \mathrm{~min}$ with a Sorvall Omnimixer (setting 10) in an ice bath. Calcium chloride (final concentration, $10 \mathrm{mM}$ ) was added to aggregate the intracellular and basolateral membranes and stirred on ice for $15 \mathrm{~min}$. The details of membrane vesicle preparation are given elsewhere $(13,14)$. Membrane vesicles were used for uptake studies on the day of preparation.

Enzyme and protein determinations. Membrane purity was routinely assessed from the enrichment of $\gamma$-glutamyltransferase and $5^{\prime}$-nucleotidase, markers for brush border membranes (16, 20). Other enzymes examined were oubain-inhibitable $\mathrm{Na}^{+} \mathrm{K}$ ATPase (28) as a marker of basolateral membranes, malate dehydroganase (26) as a marker of microsomal membranes, succinyl cytochrome $c$ reductase (35) as a mitochondrial marker, acid ( $\mathrm{pH} 4.8$ ) phosphatase (23) and $N$-acetyl- $\beta$-D-glucosaminidase (24) to indicate lysosomes, and DNA (6) as an indicator of nuclei. Protein was determined by the method of Lowry et al. (25) after precipitation in 6\% trichloroacetic acid.

Amino acid uptake studies. Uptake of radioactive taurine $\left({ }^{3} \mathrm{H}\right)$ and glucose $\left({ }^{14} \mathrm{C}\right)$ was assayed by a Millipore filtration technique (7). In general, $200 \mu \mathrm{g}$ of membrane suspension was preincubated at $25^{\circ} \mathrm{C}$ for 30 to $45 \mathrm{~min}$. Incubation was initiated by the addition of medium containing known amounts of cold and radiolabeled taurine; usually, $0.5 \mu \mathrm{Ci}$ was added. All incubation media contained $300 \mathrm{mM}$ mannitol, $1 \mathrm{mM} \mathrm{MgSO} 4,10 \mathrm{mM}$ Hepes/Tris (pH 7.4), and the other salts noted. After the desired time interval, a $50-\mu \mathrm{l}$ aliquot was placed on a prewetted $0.45-\mu$ Millipore filter (HAWP). The filtered sample was washed twice with $3.0 \mathrm{ml}$ of iced wash solution; this entire process took $12 \mathrm{sec}$. The iced "stop solution" contained $300 \mathrm{mM}$ mannitol, $1 \mathrm{mM} \mathrm{MgSO}_{4}$ and Hepes/Tris ( $\mathrm{pH}$ 7.4). Filters were dried overnight in scintillation flasks and then dissolved in Aquasol and counted for radioactivity in a liquid scintillation counter. The values for the nonspecific retention of radioactivity were subtracted from values obtained after incubation with membranes. The number of cpm obtained using $\left[{ }^{3} \mathrm{H}\right]$ taurine seldom exceeded $20 \mathrm{cpm}$ and, since more than $10^{3}$ were retained on the filter in most cases, this nonspecific retention was about $2 \%$ of the specific amount found.

All incubations were performed in triplicate. Uptake values are expressed as picomoles/mg protein/unit of time. The data at most points represent the mean of at least 12 determinations.

Effect of freezing. Since kidney cortex from adult animals can 
be frozen prior to membrane preparation without great losses in transport capacity or enzyme characteristics (21), the effect of freezing kidney cortex from 28-day-old rats in the THM-300 solution prior to preparation of the BBMV was examined. An enhancement of $\gamma$-glutamyltransferase and 5 '-nucleotidase activity of 4.8 -fold and 4.2 -fold, respectively, realtive to the starting homogenate was found in membranes from prefrozen cortex. Membranes prepared from fresh kidney cortex and then incubated in the presence of $10 \mu \mathrm{M}$ taurine and $100 \mathrm{mM} \mathrm{NaCl}$ show a typical overshoot indicative of taurine accumulation. Uptake by membranes prepared from prefrozen kidney was less than $10 \%$ of the uptake found using fresh tissue at 3 and 6 min (Fig. 1). Since uptake is so poor in prefrozen cortex, all studies were performed using fresh kidney to prepare BBMV.

Analytical. The concentration of taurine was determined on protein-free filtrates of plasma or urine using a Beckmann Model 120 amino acid analyzer, as decribed previously (11).

Data comparisons were made with Student's $t$ test, linear regression analysis, and analysis of variance using a desk-top computer with established programs (Texas Instruments Users Guide). Analysis of kinetics for transport functions was performed using the WISAR (Madison, WI) modification of the method of Neal (27). Serum and urine creatinine were measured as described (19).

Materials. $\left[{ }^{3} \mathrm{H}\right]$ Taurine (specific activity, $23.1 \mathrm{Ci} / \mathrm{mmol}$ and $\left[{ }^{14} \mathrm{C}\right]$ glucose (specific activity, $329 \mathrm{Ci} / \mathrm{mol}$ ) were purchased from New England Nuclear (Boston, MA). Radiochemical purity was confirmed by one-dimensional thin layer chromatography. All chemicals used to prepare media were reagent grade.

\section{RESULTS}

Membrane purity. Analysis of brush border membrane preparations from 28-day-old rats showed $\gamma$-glutamyltransferase and $5^{\prime}$-nucleotidase (markers of the brush border surface) were 10.1 fold and 5.7-fold enriched relative to the starting homogenate. Preparations from adult animals were 8.2-fold and 5.9-fold enriched, respectively. The relative specific activity of other cell membrane markers is shown in Table 1. No enrichment relative to the starting homogenate was found for these marker enzymes.

Effect of osmolality. At equilibrium ( $45 \mathrm{~min}$ ), the accumulation of taurine in membranes from 28 -day-old animals was inversely related to the osmolarity of the medium when sucrose was used to increase the osmolarity (fig. 2). Similar results were obtained using $60 \mu \mathrm{M}$ D-glucose (data not shown) and in membranes from adult animals $(13,14)$. These results indicate that the accumu-

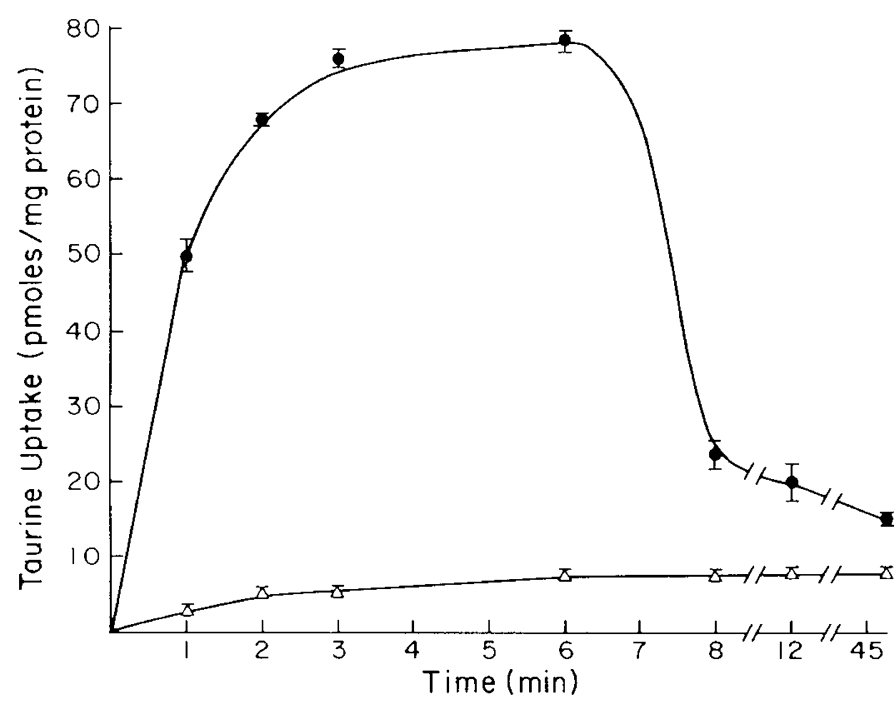

Fig. 1. Taurine accumulation over time. $\bullet$, fresh kidney cortex; $\Delta$, frozen tissue. Each point is the mean $\pm \mathrm{SE}$ of four determinations performed in triplicate.
Table 1. Marker enzyme activities in 28-day-old rat renal $B B M V$ preparation

\begin{tabular}{|c|c|c|}
\hline & $\begin{array}{l}\text { Specific activity of } \\
\text { brush border/specific } \\
\text { activity for homoge- } \\
\text { nate }\end{array}$ & $\begin{array}{l}\text { Recovery in } \\
\text { brush border } \\
\text { fractions (\%) }\end{array}$ \\
\hline$\gamma$-Glutamyltranspeptidase & $10.08 \pm 0.52 *(n=7)$ & 47.1 \\
\hline $5^{\prime}$-Nucleotidase & $5.71 \pm 0.30(n=7)$ & 26.6 \\
\hline $\begin{array}{l}\mathrm{Mg}^{2+} \text {-dependent } \mathrm{Na}^{+} \mathrm{K}-\mathrm{ATPa} \text {, } \\
\text { ouabain-sensitive }\end{array}$ & $0.73 \pm 0.05(n=7)$ & 3.4 \\
\hline Malate dehydrogenase & $0.03 \pm 0.01(n=7)$ & 0.1 \\
\hline Succinyl cytochrome $c$ reductase & $0.14 \pm 0.02(n=7)$ & 0.6 \\
\hline Acid phosphatase, pH 4.8 & $<0.03(n=7)$ & 0.1 \\
\hline DNA & $<0.03(n=7)$ & 0.1 \\
\hline
\end{tabular}

$*$ Mean \pm SE.

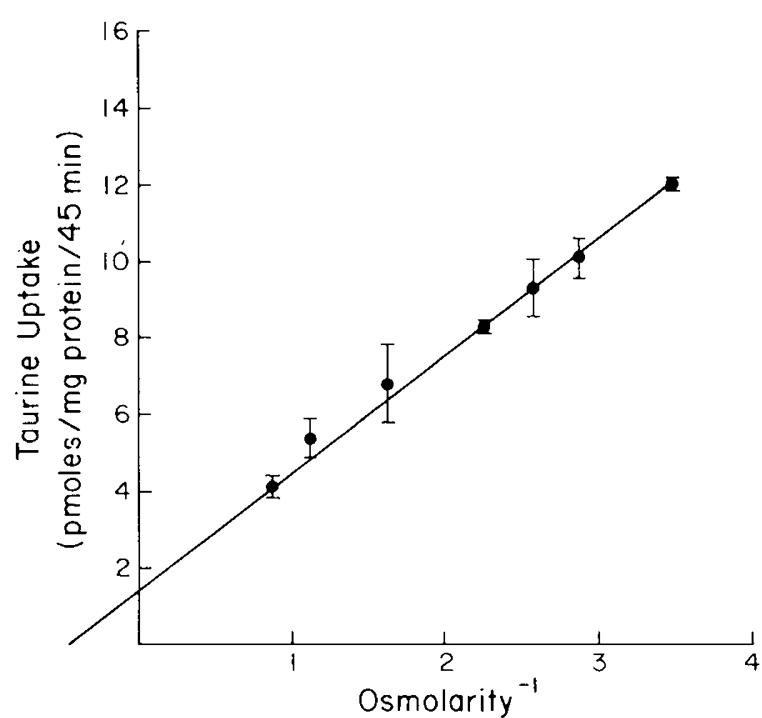

Fig. 2. The uptake of radiolabeled taurine at equilibrium from media of differing osmolarities in BBMV from 28-day-old rats. Sucrose was used to raise the medium osmolarity, and the final values ranged from 300 to $1,200 \mathrm{mosm} / \mathrm{liter}$. Each point is the mean $\pm \mathrm{SE}$ of four determinations performed in triplicate.

lation of these solutes represents intravesicular transport rather than binding to the outer surface of the membranes. As indicated in the figure, extrapolation to infinite osmolarity suggests that binding is slight compared to uptake $(<7 \%)$.

Uptake in adult and 28-day-old rat membranes. The uptakes of D-glucose and taurine by BBMV from adult and immature rat were compared. D-Glucose uptake in the presence of an external $\mathrm{Na}^{+}$gradient was more than twice as great in BBMV from adult as compared to immature animals, and the peak of the overshoot occurred earlier ( 30 versus $90 \mathrm{sec}$ ) in BBMV from adult animals (Fig. 3). These differences in the amplitude and the time of peak uptake are highly significant, $p<0.001$

By contrast, the pattern of accumulation of taurine is similar in adult and immature vesicles (Fig. 4). As noted, the accumulation of $10 \mu \mathrm{M}$ taurine at 6 min by BBMV in animals on the NTD is similar in adult $(73.8 \pm 3.1 \mathrm{pmol} / \mathrm{mg}$ protein $)$ and immature animals $(77.4 \pm 2.1)$, and the maximal accumulation is found at $6 \mathrm{~min}$ in both. Also evident is that $\mathrm{Na}^{+}$gradientdependent uptake is found in immature BBMV, since an external $\mathrm{Na}^{+}$gradient is required in order to obtain the overshoot. No overshoot is found in the absence of an external $\mathrm{NaCl}$ gradient. In addition, sonication of the BBMV blocks accumulation of taurine.

In these studies, based on four separate experiments at each age, the uptake of taurine appears to be more rapid in membranes 
from 28-day-old animals, in that accumulation is higher at 1 and $2 \mathrm{~min}$ than in adults. However, this pattern is not always evident, as reflected in the kinetic studies (Fig. 5).

Effect of diet. The influences of dietary change on the plasma and urine concentrations of taurine are shown in Table 2. Although plasma taurine concentrations were lower in animals fed the LTD for 7 days, this difference is not significant. Urine taurine concentrations and the fractional excretion of taurine were significantly lower in animals fed the LTD, indicating conservation of taurine occurs in 28-day-old animals. The HTD resulted in insignificantly higher plasma concentrations of taurine, while urinary taurine concentrations were elevated 10 -fold, significant at $P<0.001$. The fractional excretion of taurine was more than doubled, indicating that the HTD resulted in excessive taurinuria.

The effect of dietary change on the renal cortex taurine content is shown in Table 3 . The lowest tissue taurine content is found

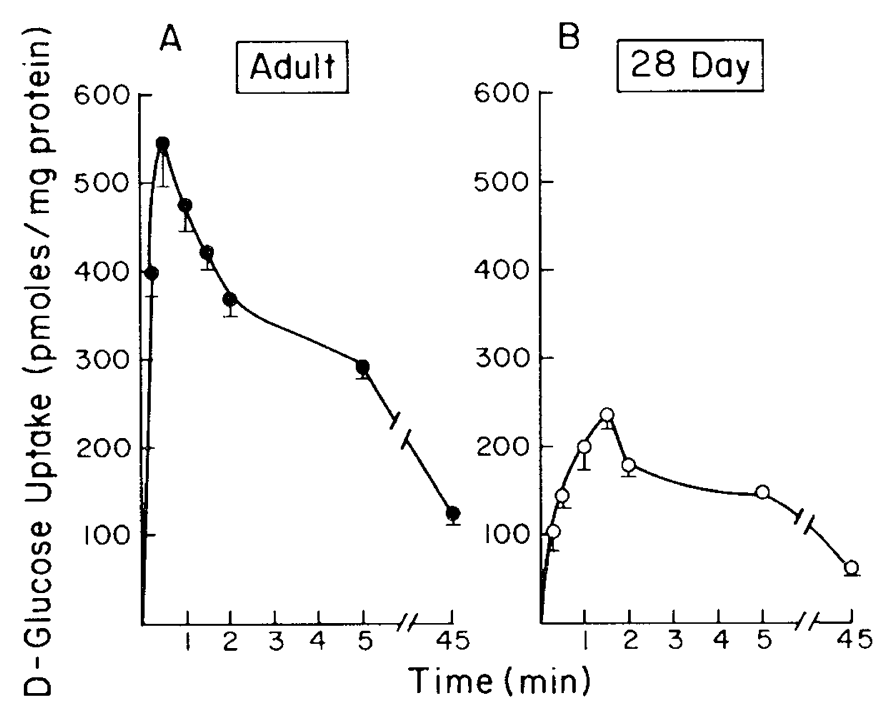

Fig. 3. D-Glucose uptake by BBMV from (-) adult and $(O)$ 28-dayold animals over time. Each point is the mean $\pm \mathrm{SE}$ of four determinations performed in triplicate. The medium concentration is $60 \mu \mathrm{M}$. in 28-day and adult animals fed the LTD for 7 and 14 days, respectively. The highest kidney taurine concentration is found in animals fed the HTD. No differences between the taurine concentration in the cortex of animals of different age, but ingesting the same diet, is evident. A variable pattern of differences in taurine content between the various diets is found. Tissues from 28-day LTD rats have a significantly lower taurine value $(P<0.05)$ than those fed the NTD or the HTD, but no significant differences exist between the NTD- and HTD-fed tissue taurine concentrations. In adult animals, the only significant difference is between the cortex content of LTD- and HTDfed animals.

When 25-day-old animals were placed on the LTD diet for only 3 days, these adaptive changes were again evident. Plasma and urine taurine concentrations were significantly reduced, as was the fractional excretion of taurine. When the values for taurine in plasma and urine and its fractional excretion were compared for each diet after 7 days on the diets (Table 2) versus 3 days on the diets (Table 4), no significant differences were observed. Indeed, the plasma value for taurine after 3 days on the LTD is significantly lower than in animals fed the NTD, a finding not made after 7 days on the diets. These data suggest that 3 days of the LTD is sufficient to observe the adaptive response. Tissue taurine concentrations in the cortex were not changed by these dietary manipulations (Table 4), probably since the length of time on the diets was short.

The accumulation of taurine by BBMV prepared from animals fed the three diets for 7 days is shown in Figure 5. This figure compares the accumulation of taurine at both 10 and $50 \mu \mathrm{M}$ over the time course of uptake. As noted, the uptake of taurine was more rapid in BBMV from animals fed the LTD than in animals fed the NTD; however, the value of uptake at 6 min was comparable. Uptake of taurine in BBMV from HTD-fed animals was lower at several time periods. These differences disappeared after $8 \mathrm{~min}$ and at equilibrium. These data suggest that the adaptation is expressed in the BBMV of 28-day-old animals.

The kinetics of taurine accumulation, over the range 10-250 $\mu \mathrm{M}$, by BBMV from immature and mature rats on each of the three diets is shown in Figure 6. At $60 \mathrm{sec}$, a time when uptake is linear so that initial rate kinetics can be estimated, the accumulation of taurine is greatest in membranes prepared from LTD-fed animals, regardless of age. This increase in uptake is

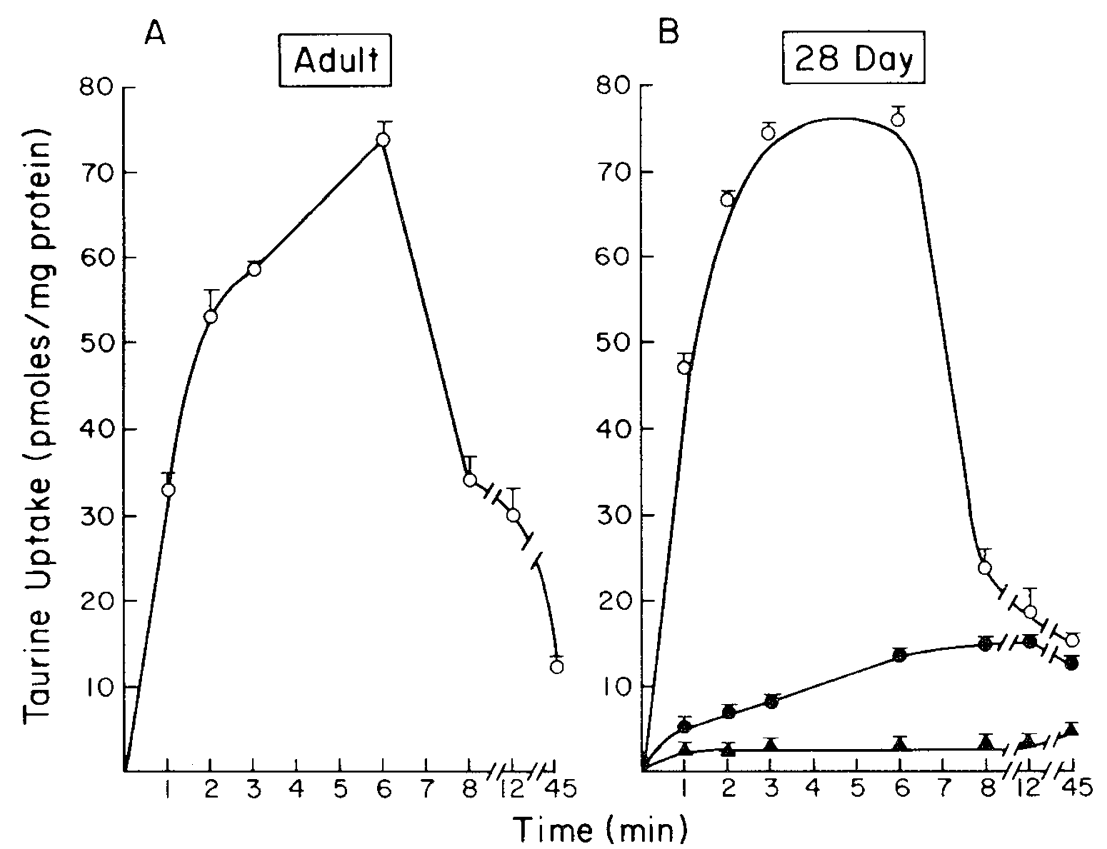

Fig. 4. Taurine uptake by BBMV from adult and 28-day-old animals. Uptake of taurine by BBMV from 28-day animals was examined in the presence of an external $100 \mathrm{mM} \mathrm{NaCl}$ gradient $(\mathrm{O})$, in the presence of $100 \mathrm{mM} \mathrm{NaCl}$ within and external to the BBMV, i.e. no gradient $(\bullet)$, and after sonication of the BBMV $(\mathbf{A})$. Each point is the mean \pm SE of four determinations performed in triplicate. 

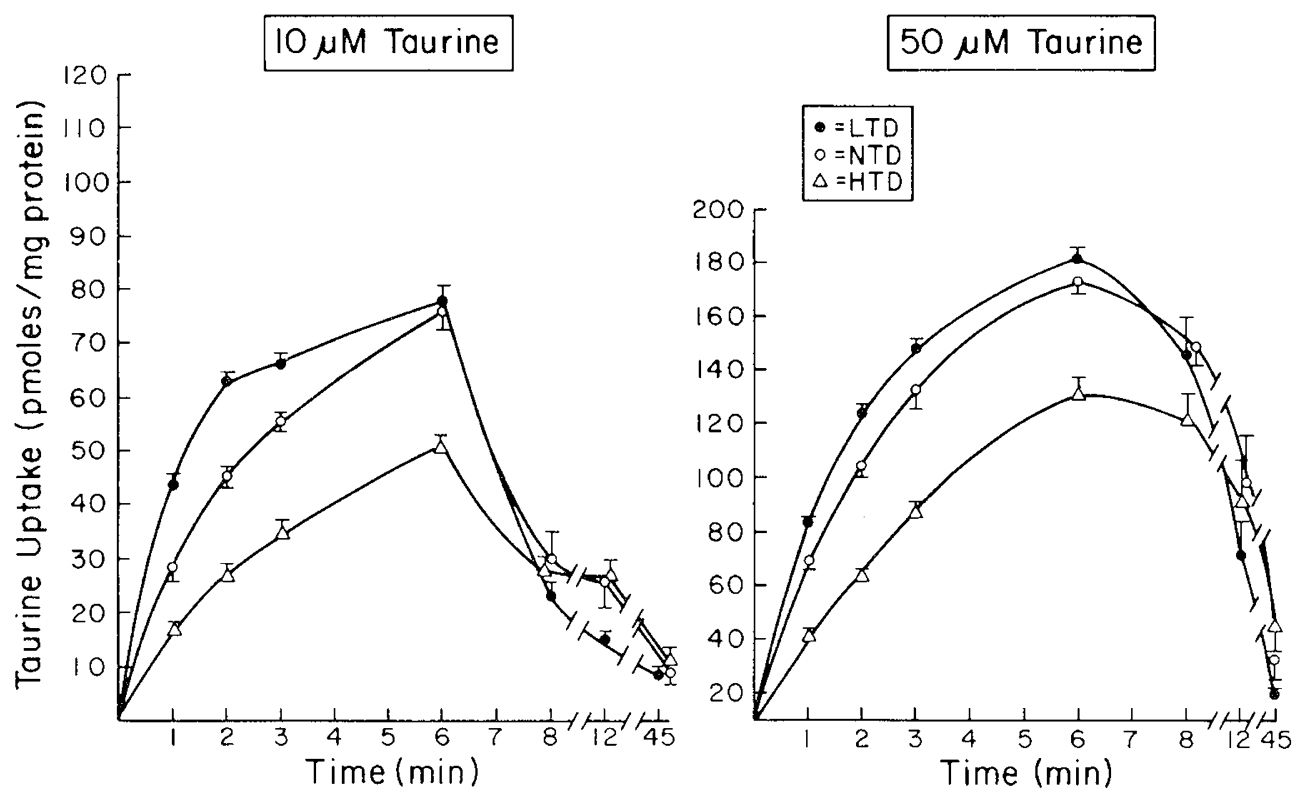

Fig. 5. Uptake of taurine over time at 10 and $50 \mu \mathrm{M}$ taurine. Each point is the mean \pm SE of four determinations performed in triplicate. Values obtained in animals fed the LTD are significantly higher $(p<0.01)$ at 1,2 , and $3 \mathrm{~min}$ at both concentrations. Values obtained in animals fed the HTD are significantly lower $(p<0.01)$ at $1,2,3$, and 6 min at both concentrations.

Table 2. Plasma and urine concentrations of taurine in 28-day-old rats on the various diets*

\begin{tabular}{lccc}
\hline & LTD & NTD & HTD \\
\hline Immature $(28$ days) & & & \\
Plasma $\mu$ mol/liter plasma $\mathrm{H}_{2} \mathrm{O}$ & $136.98 \pm 12.78^{a}$ & $247.8 \pm 70.9$ & $391.41 \pm 46.84^{a}$ \\
& $n=10$ & $n=10$ & $271.68 \pm 32.06^{c}$ \\
Urine $\mu \mathrm{mol} / \mathrm{mg}$ creatinine & $2.416 \pm 0.756^{b}$ & $27.04 \pm 7.42^{d}$ & $n=10$ \\
& $n=10$ & $n=10$ & $0.7452 \pm 0.0829^{b}$ \\
Fractional excretion of taurine & $0.0138 \pm 0.0033^{c}$ & $0.3257 \pm 0.0574^{d}$ & $n=10$ \\
& $n=10$ & $n=10$ & $1195 \pm 87^{c}$ \\
Adult $(58-60$ days) & $182 \pm 20^{b}$ & $321 \pm 29$ & $n=13$ \\
Plasma $\mu$ mol/liter plasma $\mathrm{H}_{2} \mathrm{O}$ & $n=24$ & $n=23$ & $184.1 \pm 30.8^{c}$ \\
Urine $\mu$ mol/mg creatinine & $0.56 \pm 0.19^{c}$ & $n .36 \pm 1.08$ & $n=13$ \\
Fractional excretion of taurine & $n=25$ & $n=12$ & $0.6255 \pm 0.0802^{c}$ \\
& $0.0179 \pm 0.0005^{c}$ & $0.0976 \pm 0.0016$ & $n=13$ \\
\hline
\end{tabular}

* $P$ values are keyed as follows: ${ }^{a}$ not different from NTD $;{ }^{b}$ different from NTD, $P<0.01 ;{ }^{c}$ different from NTD, $P<0.001 ;{ }^{d}$ different from adult values, $P<0.01$. Data are expressed as mean $\pm \mathrm{SE}$.

$\dagger$ These data are from Ref. 14.

Table 3. Taurine concentration in renal cortex of 28-day-old

\begin{tabular}{lccc}
\multicolumn{4}{c}{ and adult rats } \\
\hline & 28-Day & Adult & $P$ \\
\hline Low taurine diet (A) & $4.24 \pm 0.68$ & $4.60 \pm 0.6$ & NS \\
& $n=10$ & $n=13$ & \\
Normal taurine diet (B) & $8.56 \pm 0.88$ & $8.76 \pm 1.6$ & NS \\
& $n=7$ & $n=6$ & \\
High taurine diet (C) & $12.72 \pm 2.96$ & $18.96 \pm 5.36$ & NS \\
& $n=10$ & $n=12$ & \\
\hline
\end{tabular}

*Values are expressed in $\mu \mathrm{mol} / \mathrm{g}$ cortex (wet weight), given as mean \pm SE. NS, not significant. Statistics: 28-day: A vs. B, $P<0.05$; A vs. C, $P<0.05$; B vs. C, NS. Adult: A vs. B, NS; A vs. C, $P<0.05$; B vs. C, NS.

due to a change in $V_{\max }$, rather than an alteration in $\mathrm{K}_{\mathrm{m}}$. The reduction in uptake by vesicles from HTD animals is also related to a change in $\mathrm{V}_{\max }$ (Table 5). Using an analysis of variance, no difference in the $\mathrm{K}_{\mathrm{m}}$ of uptake was found, regardless of age or diet, but the $V_{\max }$ was higher in LTD vesicles and lower in HTD vesicles than in NTD vesicles $(P<0.01)$. The slope of the Lineweaver-Burk plots do not differ between ages, but are differ-
Table 4. Plasma and urine taurine concentrations after 3 days

\begin{tabular}{|c|c|c|c|}
\hline \multicolumn{4}{|c|}{ on diet* } \\
\hline & LTD & NTD & $P$ \\
\hline \multirow[t]{2}{*}{$\begin{array}{l}\text { Plasma } \mu \mathrm{mol} / \text { liter } \\
\text { plasma } \mathrm{H}_{2} \mathrm{O}\end{array}$} & $124.41 \pm 2.65$ & $208.1 \pm 20.4$ & $<0.01$ \\
\hline & $n=3$ & $n=3$ & \\
\hline \multirow[t]{2}{*}{$\begin{array}{l}\text { Urine } \mu \mathrm{mol} / \mathrm{mg} \text { creati- } \\
\text { nine }\end{array}$} & $3.86 \pm 0.79$ & $27.6 \pm 7.5$ & $<0.01$ \\
\hline & $n=3$ & $n=3$ & \\
\hline $\begin{array}{l}\text { Fractional excretion of } \\
\text { taurine }\end{array}$ & $0.0342 \pm 0.0083$ & $0.1853 \pm 0.0490$ & $<0.05$ \\
\hline \multirow{2}{*}{$\begin{array}{l}\text { Tissue } \mu \mathrm{mol} / \mathrm{g} \text { cortex } \\
\text { (wet weight) }\end{array}$} & $8.00 \pm 0.94$ & $5.56 \pm 0.42$ & $<0.05$ \\
\hline & $n=3$ & $n=3$ & \\
\hline
\end{tabular}

* Results are expressed as mean $\pm \mathrm{SE}$.

ent by analysis of variance on each diet: LTD: 28-day, 0.0023, adult, 0.0033; NTD: 28-day, 0.0063, adult, 0.0072; HTD: 28day, 0.0083 , adult, 0.0081 . The slopes of values on each diet differ from each other at $P<0.01$.

The kinetics at the high $\mathrm{K}_{\mathrm{m}}$ uptake site over the range 0.5 to 
$5.0 \mathrm{mM}$ are shown in Figure 7. The differences at this site are not as marked, although the highest uptake is found in BBMV from LTD animals and the lowest in BBMV from HTD. The $\mathrm{K}_{\mathrm{m}}$ of uptake at this site is approximately $6.6 \mathrm{mM}$. The accumulation at $5.0 \mathrm{mM}$ is as follows: LTD, $1660.8 \pm 106 \mathrm{pmol} / \mathrm{mg}$ protein $/ 60 \mathrm{sec}$; NTD, $1464.6 \pm 96 \mathrm{pmol} / \mathrm{mg}$ protein $/ 60 \mathrm{sec}$; HTD, $1262 \pm 86 \mathrm{pmol} / \mathrm{mg}$ protein $/ 60 \mathrm{sec}$. These differences are not statistically different.

The effects of these three diets on D-glucose accumulation are
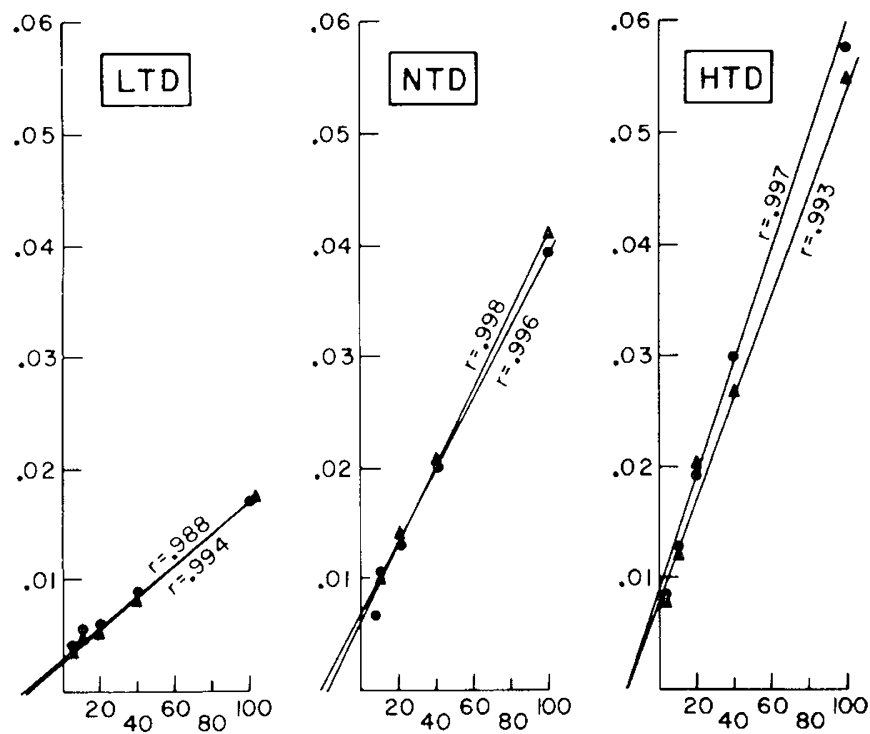

Fig. 6. Lineweaver-Burk analysis of uptake data into BBMV in animals fed each diet. The concentrations examined vary from 10 to 250 $\mu \mathrm{M}$. Uptake was examined over $60 \mathrm{sec}$. Each point is the mean of four determinations performed in triplicate. $\boldsymbol{\bullet}$, adult; $\mathbf{\Lambda}, 27-28$-day. Ordinate is $1 / v(\mathrm{pmol} / \mathrm{mg}$ protein $/ 60 \mathrm{sec}$ ); abscissa is $1 / \mathrm{s}$ (taurine concentration $\left.\times 10^{-3}\right)$.

Table 5. Kinetics of accumulation by brush border membrane vesicles*

\begin{tabular}{lrrc}
\hline & LTD & NTD & HTD \\
\hline $\mathrm{K}_{\mathrm{m}} \dagger$ for 28-day & 50.6 & 55.4 & 55.5 \\
$\mathrm{~K}_{\mathrm{m}}$ for adult & 40.8 & 44.9 & 58.5 \\
$\mathrm{~V}_{\max } \ddagger$ for 28-day & $357 \S$ & 142.8 & $125 \S$ \\
$\mathrm{V}_{\max }$ for adult & $333 \S$ & 156.2 & $114 \S$ \\
\hline
\end{tabular}

* The mean value of four experiments, with each point performed in triplicate.

$+\mathrm{K}_{\mathrm{m}}=\mu \mathrm{M} /$ liter

$\ddagger \mathrm{V}_{\text {max }}=$ pmol uptake $/ \mathrm{mg}$ protein $/ 60 \mathrm{sec}$

$\S$ Different from NTD value, $P<0.01$.

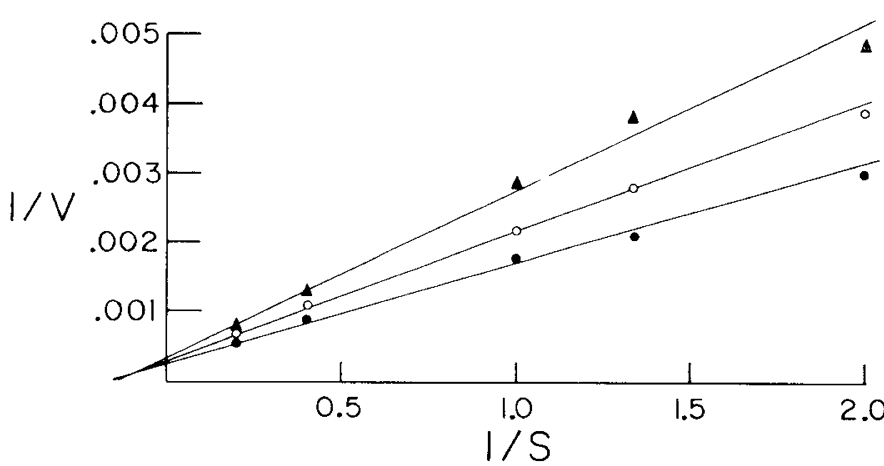

Fig. 7. Lineweaver-Burk analysis of uptake data into BBMV in animals fed each diet. The concentrations examined varied from 0.5 to 5.0 $\mathrm{mM}$. Uptake was examined over $60 \mathrm{sec}$. Each point is the mean of four determinations performed in triplicate. $\bullet$, LTD; O, NTD; $\mathbf{\Lambda}$, HTD. shown in Figure 8. No significant change in the uptake of this sugar by BBMV prepared from animals fed each of the diets was evident. Although the initial rate of uptake of D-glucose (20 and $40 \mathrm{sec}$ ) appears to be greater in BBMV from LTD-fed rats, the higher values do not achieve statistical significance.

\section{DISCUSSION}

The immature mammalian kidney is not fully capable of reabsorbing amino acids, and a generalized aminoaciduria results $(2,33)$. Among the amino acids that are hyperexcreted, taurine is a prominent substance in both rodents (11) and man (10). This decreased reclamation of amino acids could occur as the result of at least two processes, either together or singly: 1) the delayed development of a transport site for a given amino acid $(2,3)$, or 2$)$ a decreased number of uptake sites per nephron (33). The former process would demonstrate a change in $\mathrm{K}_{\mathrm{m}}$ or affinity of the carrier for the substrate (amino acid) with maturation; the latter process would imply a change in the $\mathrm{V}_{\max }$ of accumulation. The mechanism of neonatal taurinuria in slices (12) and tubules (18) appears to involve a decreased initial rate of uptake with a reduction in the $\mathrm{V}_{\max }$ of taurine accumulation. A third mechanism, decreased efflux at the basolateral membrane in immature cortex, also appears to be relevant $(2,3,10,12,18,33)$, but the kinetic characteristics of this diminished rate of exit are not clear. Finally, changes in "effective intravascular volume" may influence the transport of organic solutes (21).

We have used the isolated BBMV system to further define the ontogeny of glucose and amino acid reaccumulation. The studies reported herein indicate that BBMV can be prepared from the cortex of 28-day-old rats. Rats of this age were chosen, since they can be fed the various diets of interest and since they are no longer nursing. Our previous studies of ontogeny have examined neonatal rats (18) as well as 14-day and 28-day animals $(11,12)$. Hence, we have a precedent for using 28-day-old rats for studies of ontogeny.

A 10 -fold increase in $\gamma$-glutamyltransferase was found, with a reduction in marker enzymes from other subcellular organelles. Further, these vesicles are osmotically active, indicating accumulation of taurine or glucose rather than binding to the outer surface of the membrane. As in studies of adult animals, this uptake is $\mathrm{Na}^{+}$-dependent, as no overshoot is found in the absence of an external $\mathrm{Na}^{+}$gradient $(13,14,31,32)$. Sonication, as expected, blocks the uptake of taurine and prevents a typical overshoot pattern.

Maturational changes were found in glucose accumulation by BBMV prepared from 28-day-old rats. At $60 \mu \mathrm{M}$ D-glucose, the peak of the overshoot is lower, and the time course of uptake is shifted to the right. We did not perform concentration-dependent

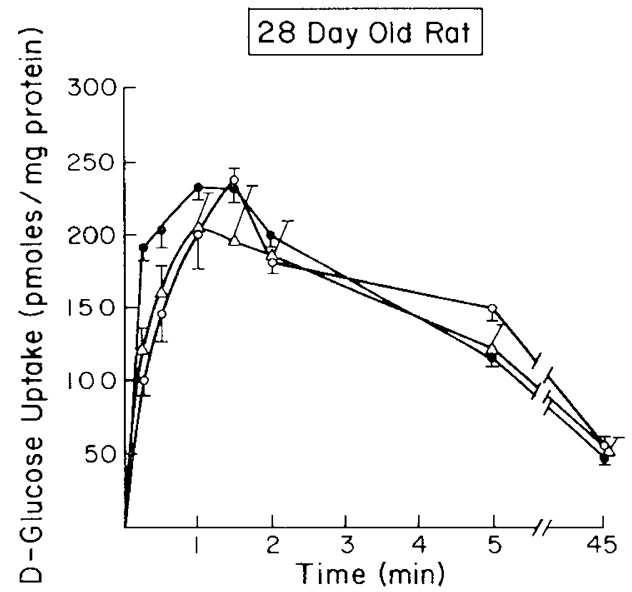

Fig. 8. Uptake of D-glucose over time by BBMV from animals on each diet. Each point is the mean $\pm \mathrm{SE}$ of four determinations performed in triplicate. The medium concentration is $60 \mu \mathrm{M}$. 
studies, so we do not know if the kinetics of accumulation are altered by immaturity. The reduction in the maximal tubular reabsorption of glucose found in the immature kidney has been known since the late 1940s (38). Although Tudvad (38) felt that the maximal reabsorption was reduced even for the low glomerular filtration rate of infants, recent studies have indicated that the maximal glucose reabsorption per milliliter of glomerular filtrate is equal to adult levels during infancy in man (5), in dog (1), and in sheep, even during the fetal period (29). Preliminary studies in BBMV in newborn rabbit (8) and guinea pig (34) indicate that the $\mathrm{V}_{\max }$ of uptake of D-glucose is lower than in adults. However, neonatal rat and guinea pig appear to have a unique high affinity, low capacity, $\mathrm{Na}^{+}$-dependent uptake system not found in adult vesicles (34) or isolated tubules (30). This second glucose transport site may serve to conserve glucose and thus prevent the loss of nutrients during a rapid growth phase. Certainly, glucosuria is not a feature of immaturity $(1,29)$. However, the reduction in glucose accumulation found in this study in rats is consistent with the above enumerated findings in other mammals.

Taurine excretion is greater in 28-day-old animals $(27 \mu \mathrm{mol} /$ mg creatinine) in comparison to the values in 58-60-day-old animals of $6.36 \pm 1.08 \mu \mathrm{mol} / \mathrm{mg}$ creatinine (14). As well, the fractional excretion of taurine is greater in immature animals: 35.5 versus $9.8 \%$ in adults.

We have used the adaptive response of kidney cortex to alteration in sulfur-amino acid dietary conumption as a further probe of the maturation process in rat kidney. The young rats were fed each diet for 7 days, in contrast to 14 days of diet in the adult rats. Yet, this time difference is probably unimportant for several reasons. First, the adaptive response was noted in adult rats after 6 days on each diet $(13,14)$. Second, the young rats were still nursing until age 21 days and, prior to that time, it is unclear if the nursing mother will exhibit a different pattern or profile of sulfur-amino acids in her milk. Third, it is probable that the adaptive response to diet will be expressed after only 3 days on each diet (Table 4). Finally, the differences found in tissue taurine content in animals on each diet are comparable in adult animals fed the diet for 14 days and in 28-day-old rats fed for 7 days. The 28-day-old rat has decreased excretion of taurine with the LTD and enhanced excretion of the HTD.

The findings of significant changes in plasma concentrations of taurine between animals fed the LTD for 3 days and those fed the NTD for the same amount of time is consistent with differences in plasma taurine values found by us in adult animals (13 $14,19)$ and by Rozen et al. (32) in mice. The changes in plasma concentration in 28-day-old animals fed each diet for 7 days were not significantly different, possibly since the SD for plasma level in the NTD group was quite high. Nonetheless, those $28-$ day-old rats fed the LTD had the lowest plasma values (mean, $134 \mu \mathrm{mol} /$ liter plasma $\mathrm{H}_{2} \mathrm{O}$ ) and those fed the HTD had the highest $\left(391 \mu \mathrm{mol} /\right.$ liter plasma $\mathrm{H}_{2} \mathrm{O}$ ). After excluding those plasma values that are beyond $2 \mathrm{SD}$ from the mean, the new mean $\pm \mathrm{SE}$ value for taurine in plasma from NTD-fed, 28-dayold rats is $329 \pm 26 \mu \mathrm{mol} /$ liter plasma $\mathrm{H}_{2} \mathrm{O}$. This new value is significantly higher than the value in animals fed the LTD $(P<$ 0.005 ) but not different from the values in HTD-fed rats.

These differences are reflected at the brush border surface early in the time course of uptake. Hence, this renal adaptive response is found in immature rat kidney and is expressed at the luminal surface. However, these diets do slightly alter glucose accumulation by BBMV, in that the LTD resulted in increased initial uptake of D-glucose at 20 and $40 \mathrm{sec}$. A similar observation was made by Rozen et al. (32), suggesting that the adaptive response may extend beyond taurine in these experiments. Nonetheless, the magnitude of change is greatest for taurine uptake by BBMV.

The kinetics of initial taurine uptake by BBMV at the low $\mathrm{K}_{\mathrm{m}}$ site from animals on each of the three diets indicate that an alteration in the $\mathrm{V}_{\text {max }}$ of uptake, but not in the $\mathrm{K}_{\mathrm{m}}$, can account for the changes in accumulation regardless of the age of the animal, that is, 28-day versus adult. Over the range 0.5 to 5.0 $\mathrm{mM}$, the uptake is highest in vesicles prepared from animals on the LTD, but the differences are much smaller than those found at the lower concentration range.

Although changes in accumulation related to diet are abvious, no age-related differences in either $K_{m}$ or $V_{m a x}$ are observed in 28-day versus adult rat BBMV. Therefore, the differences in urinary taurine excretion found in vitro (Table 2) between 28day and 58-60-day-old animals cannot be explained by changes in the initial rate of uptake by BBMV. Indeed, in some time course experiments, the initial (1- and 2-min) uptake was more brisk in tubules from the young animals. The differences we observed in our previous studies $(12,18)$ would indicate that the efflux of taurine out of the slice or isolated tubule is impaired in immature animals. Since efflux is presumably occurring at the basolateral membrane surface, studies of transport differences in isolated basolateral membrane would appear to be important. Nevertheless, when the 28-day animal is placed on a diet devoid of or enriched by sulfur-amino acids, changes in brush border surface uptake reflect the changes in urinary excretion pattern. Hence, the changes in the adaptive response, occurring at the brush border membrane, are actually separate from the developmental changes that occur under normal physiologic conditions and on a usual diet at the basolateral surface.

In conclusion, BBMV can be prepared from 28-day-old rat kidney cortex which accumulates both D-glucose and taurine in $\mathrm{Na}^{+}$-dependent fashion. The uptake of $\mathrm{D}$-glucose is lower in membranes from 28 -day-old animals than in those from adults. The accumulation of taurine has a similar pattern, and the $V_{\max }$ of uptake is similar. Thus, the taurinuria found in young animals is not expressed at the brush border surface, but more likely represents an efflux block, as we have previously shown in slices (12) or tubules (18). Immature rats adapt to changes in dietary sulfur-amino acid intake which may serve to conserve amino acids in periods of undernutrition and excrete excess amino acids during periods of dietary excess, and this adaptive response is expressed at the brush border surface by a separate process.

\section{REFERENCES AND NOTES}

1. Arant BS, Jr 1978 Glomerulotubular balance following saline loading in the developing canine kidney. Am J Physiol 235:F417

2. Baerlocher KE, Scriver CR, Mohyuddin F 1971 The ontogeny of amino acid trnsport in rat kidney. I. Effect on distribution ratios and intracellular metabolism of proline and glycine. Biochim Biophys Acta 249.353

3. Baerlocher KE, Scriver CR, Mohyuddin F 1971 The ontogeny of amino acid transport in rat kidney. II. Kinetics of uptake and effect of anoxia. Biochim Biophys Acta 249:364

4. Booth AG, Kenny AJ 1974 A rapid method for the preparation of microvilli from rabbit kidney. Biochem J 142.575

5. Brodehl J, Gellissen K 1968 Endogenous renal transport of free amino acids in infancy and childhood. Pediatrics 42:395

6. Burton K 1956 A study of the conditions and mechanism of the diphenylamine reaction for the colorimetric estimation of deoxyribonucleic acid. Biochem J $62: 315$

7. Chesney RW, Sacktor B, Rowen RR 1973 The binding of D-glucose to the isolated rabbit renal brush border. J Biol Chem 218:2182

8. Chesney RW, Sacktor B 1974 Developmental characteristics of rabbit renal cortex membranes. Pediatr Res 8:454A

9. Chesney RW, Scriver CR, Mohyuddin F 1976 Localization of the membrane defect in transepithelial transport of taurine by parallel studies in vivo and in vitro in hypertaurinuric mice. $\mathrm{J}$ Clin Invest 57:183

10. Chesney RW, Jax DK, Scriver CR, Mohyuddin F 1978 Taurine transport in mammalian kidney. In: Huxtable R, Barbeau A (eds): Taurine in Neurological Disorders. New York, Raven Press, pp 73-94

11. Chesney RW, Jax DK 1979 Developmental aspects of renal $\beta$-amino acid transport. I. Ontogeny of taurine reabsorption and accumulation in rat renal cortex. Pediatr Res 13:854

12. Chesney RW, Jax DK 1979 Developmental aspects of renal $\beta$-amino acid transport. II. Ontogeny of uptake and efflux processes and effect of anoxia. Pediatr Res 13:861

13. Chesney RW, Friedman AL, Albright PW, Gusowski N 1982 Fasting reverses the renal adaptation to altered dietary amino acid intake. Proc Soc Exp Biol Med 170:493

14. Chesney RW, Gusowski N, Friedman AL 1983 Renal adaptation to altered dietary sulfur amino acid intake occurs at the luminal brush border membrane. Kidney Int 24:588

15. Dirks JH. Seely JF, Levy M 1976 Control of extracellular fluid volume and 
the pathophysiology of edema formation. In: Brenner BM, Rector FC (eds): The Kidney. Philadelphia, WB Saunders Co, pp 495-522

16. Dixon TF, Purdom M 1954 Serum 5-nucleotidase. J Clin Pathol 7:341

17. Friedman AL, Albright PW, Chesney RW 1981 Dietary adaptation of taurine transport by rat renal epithelium. Life Sci 29:2415

18. Friedman AL, Jax DK, Chesney RW 1981 Developmental aspects of renal $\beta$ amino acid transport. III. Characteristics of transport in isolated renal tubules. Pediatr Res 15:10

19. Friedman AL, Albright PW, Gusowski N, Padilla M, Chesney RW 1983 Rena adaptation to alteration in dietary amino acid intake. Am J Physiol 245:F159

20. Glossman H, Neville DM, Jr $1972 \gamma$-Glutamyltransferase in kidney brush border membranes. FEBS Lett 19:340

1. Hilden SA, Sacktor B 1978 Preservation of renal brush border membrane transport function by storage in glycerol. Kidney Int 14:279

22. Huxtable RJ 1981 Insights on function: metabolism and pharmacology of taurine in the brain. In Lombardini JB, Kenney $\mathrm{AD}$. (eds): The Role of Peptides and Amino Acids as Neurotransmitters, New York, Alan R. Liss Inc, pp 53-97

23. Kildovsky O 1971 Developmental changes of $\beta$-galactosidase and $\beta$-glucuronidase in the rat liver and kidney. Arch Biochem Biophys 142:378

24. Kunin CM, Chesney RW 1978 Enzymuria as a marker of renal injury and disease: studies of $\mathrm{N}$-acetyl- $\beta$-glucosamidase in defined renal diseases of childhood. Pediatrics 62:751

25. Lowry OH, Rosebrough NJ, Farr AL, Randall RJ 1951 Protein measurement with the Folin phenol reagent. J Biol Chem 193:265

26. Lowry OH, Passonneau JV 1972 A Flexible System of Enzymatic Analysis. New York, Academic Press, pp 201-204

27. Neal JL 1972 Analysis of Michaelis kinetics for two independent saturable membrane transport functions. J Theor Biol 35:113

28. Post RL, Sen AK 1981 Sodium and potassium-stimulated ATPase. Methods Enzymol 10:762

29. Robillard JE, Sessions C, Kennedy RL, Smith FG, Jr 1978 Maturation of the glucose transport process by the fetal kidney. Pediatr Res 12:680
30. Roth KS, Hwang SM, Yudkoff M, Segal S 1978 The ontogeny of sugar transport in kidney. Pediatr Res 12:1127

31. Rozen R, Tenenhouse HS, Scriver CR 1979 Taurine transport in renal brush border membrane vesicles. Biochem J 180:245

32. Rozen R, Scriver CR 1982 Renal transport of taurine adapts to perturbed taurine homeostasis. Proc Natl Acad Sci USA 79:210

33. Segal S 1982 Regulatory aspects of transport during development. In: Spitze A (ed): The Kidney during Development: Morphology and Function. New York, Masson Publishing, p 363

34. Seigle R, Kinne R, Spitzer A 1982 Glucose transport in newborn guinea pig brush border membrane fragments. Kidney Int 21:287A

35. Sottocassa GL, Kuylenstierna B, Ernster L 1967 An electron transport system associated with the outer membrane of liver mitochondria: a biological and morphological study. J Cell Biol 32:415

36. Steele TH, DeLuca HF 1976 Influence of the dietary phosphorus on renal phosphate reabsorption in the parathyroidectomized rat. J Clin Invest 57:867

37. Trohler J, Bonjour JP, Fleisch H 1976 Inorganic phosphate homeostasis: renal adaptation to the dietary intake in intact and thyroparathyroidectomized rats. J Clin Invest 57:264

38. Tudvad F 1949 Sugar reabsorption in premature and full-term babies. Scand J Clin Lab Invest 1:28

39. Wen GY, Sturman JA, Wisniewski HM Lidsky AA Cornwell AC Hayes KC 1979 Tapetum disorganization in taurine-depleted cats. Invest Ophthalmol Visual Sci 18:1201

40. This research was supported by funds from the Medical School and Graduate School Research Committees, University of Wisconsin. Dr. Chesney is the recipient of Research Career Development Award, KO4-AM00421 from the National Institutes of Health.

41. Requests for reprints should be addressed to: Russell W. Chesney, M.D. Department of Pediatrics, University of Wisconsin Hospitals, 600 Highland Avenue, Madison, WI 53792.

42. Received for publication December 13,1982

43. Accepted for publication August 10, 1983.

\title{
Effects of Nitroprusside on Cardiac Function, Blood Flow Distribution, and Oxygen Consumption in the Conscious Young Lamb
}

\author{
JAAP R. G. KUIPERS, ${ }^{(34)}$ DANIEL SIDI,,${ }^{(35)}$ MICHAEL A. HEYMANN, AND \\ ABRAHAM M. RUDOLPH ${ }^{(36)}$ \\ Cardiovascular Research Institute and the Departments of Pediatrics, Physiology, and Obstetrics, Gynecology \\ and Reproductive Sciences, University of California, San Francisco, California USA
}

\section{Summary}

Resting cardiac output is high relative to body weight during the neonatal period and there is a limited reserve for further increasing cardiac output. We assessed the effect on the circulation of reducing peripheral vascular resistance by infusing high doses of sodium nitroprusside in 1- and 3-week-old lambs. In a dose of $5 \mu \mathrm{g} \cdot \mathrm{kg}^{-1} \cdot \mathrm{min}^{-1}$ over $1 \mathrm{~h}$, nitroprusside caused a decrease in aortic and left atrial pressure, an increase in heart rate, and no significant changes in cardiac output or oxygen consumption. Infusing $10 \mu \mathrm{g} \cdot \mathrm{kg}^{-1} \cdot \mathrm{min}^{-1}$ for $2 \mathrm{~h}$ resulted in an initial marked decrease in aortic pressure, cardiac output, and also heart rate. Within 50 min aortic pressure gradually increased, but was still well below control levels, while cardiac output returned to control level and heart rate slowly increased. Distribution of cardiac output and organ blood flows was measured by the radionuclide microsphere method. Blood flows to the kidneys and to the skin fell markedly, but flows to other organs did not change significantly.

Sodium nitroprusside has been shown to be beneficial in the medical management of patients with acute or chronic heart failure $(1,8,10,20,21,24)$. Positive effects were attributed to a reduction in systemic vascular impedance or left ventricular afterload caused by arteriolar vasodilatation and to a reduction in preload secondary to venodilatation (29). Reduction in preload, however, can also result from the additional effects of nitroprusside on myocardial relaxation (6), left ventricular diastolic properties (7), and alterations in pulmonary venous compliance (32). The precise mechanisms by which nitroprusside alters the hemodynamics in physiological and pathological situations are still not completely understood; yet nitroprusside is widely used clinically. Experience with nitroprusside in the pe- 